\title{
Effect of basil seed gum, xanthan gum and carrageenan on rheological and sensory properties of suspended barberry pulp in syrup
}

\author{
Maryam Maleki ${ }^{1}$, Seyyed Ali Mortazavi ${ }^{1}$, \\ Samira Yeganehzad ${ }^{2}$, Ahmad Pedram Nia ${ }^{1}$
}

\author{
1 - Islamic Azad University, Sabzevar Branch, Sabzevar, Iran \\ 2 - Research Institute of Food Science and Technology, Mashhad, Iran
}

\section{Keywords: \\ Barberry \\ Carrageenan \\ Basil \\ Xanthan \\ Gum \\ Rheology}

\section{Article history:}

Received 19.02.2019

Received in revised form 09.09.2019

Accepted 28.11.2019

\section{Corresponding authors:}

Samira Yeganehzad Email:

s.yeganehzad@ rifst.ac.ir

DOI: $10.24263 / 2304-$ 974X-2019-8-4-14

\section{Abstract}

Introduction. Berberis vulgaris is a native plant in Iran and the seedless type gained a reputation for the southern regions of Khorasan. The effect of adding mixture of basil seed gumcarrageenan and xanthan-carrageenan gum on rheological behavior and stability of suspended barberry pulp in syrup was investigated.

Materials and methods. Sugar $4.8 \%(\mathrm{w} / \mathrm{v})$, glucose syrup $21 \%(\mathrm{w} / \mathrm{v})$, barberry concentrate $17 \%(\mathrm{w} / \mathrm{v})$, water $54 \%(\mathrm{w} / \mathrm{v})$, and barberry pulps $2 \%(\mathrm{w} / \mathrm{v})$ were weighed. Different ratios of hydrocolloids $(1.20 \%(\mathrm{w} / \mathrm{v}))$, including basil seed gumcarrageenan and xanthan-carrageenan were prepared. The gum solution and other ingredients were heated to $60{ }^{\circ} \mathrm{C}$ for 10 minutes. To prepare the final product, the pulps of barberry were directly added to the solution. Rheological and sensory properties were evaluated.

Results and discussion. The highest apparent viscosity belonged to sample with $100 \%$ basil seed gum, and the lowest value was for the sample containing 100\% carrageenan. Samples containing xanthan-carrageenan had lower apparent viscosity compared to sample with basil seed gum-carrageenan. Increasing the amount of basil seed gum by formation of a three-dimensional network of continuous phase increases viscosity and make suitable conditions for suspending barberry pulp. It was found that the most suitable model for predicting the flow behavior of the samples was the Herschel-Bulkley model. Samples containing $70 \%$ basil seed gum and $30 \%$ carrageenan, due to the proper appearance and appropriate suspension of barberry particles, gained the highest scores in terms of sensory properties by the panelists and the lowest scores belonged to the sample containing $100 \%$ xanthan gum. The samples containing $100 \%$ basil seed gum and $100 \%$ xanthan gum showed the highest density and the lowest density, respectively.

Conclusions. According to the results obtained the sample containing $70 \%$ basil seed gum and $30 \%$ carrageenan showed the highest score in terms of sensory properties, stability and suspension assessment compared to other sample and could be introduced as a suitable formulation of barberry suspended pulp in the syrup. 


\section{Introduction}

Barberry is a large group of evergreen barbed shrubs that are very important because of their many uses and applications, such as fruit consumption. Barberry with scientific name Berberis vulgaris is a native plant in Iran and the seedless type gained a reputation for the southern regions of Khorasan, especially Qaen and Birjand (Figure 1) [1].

In all parts of barberry plant, there are Berberine, Oxycontin and Berbamine alkaloids. The amount of alkaloids in the root of the barberry is more than other parts of the plant. Barberry fruit contains about $4 \%$ cinnamon, $65 \%$ malic acid and tartaric acid and some gum [1]. Barberry has phenolic compounds (725.558 $\mathrm{mg}$ of gallic acid in $100 \mathrm{ml}$ of extract), anthocyanin (208.392 mg / 1), antioxidant activity (84.26\%) and vitamin C [2].

A global look at barberry is primarily a medicinal plant that has the potential for extraction of active ingredients, and the second look is an ornamental plant. Medicinal herbs containing Berberine have been used predominantly as antidiarrheal during a thousand-year period in China and India [1].

The consumption of barberry in freshly form because of sour taste is not common. Innovations in the production of barberry products and the production of various pulp products such as jam, marmalade, juice, soft drinks, pasta, sauce, jelly or hydrogel are growing nowadays.

Hydrocolloids are used in the formulation of fruit snacks to increase stability due to the ability to maintain water, improve the texture, and affect flavor release and other structural and sensory properties in the desired product [3].

Basil (Ocimum bacilicum) is a member of the family of mint, a species that is spread in Iran. According to the report of Iran to the International Conference on Genetic Resources FAO (1996), basil plant is introduced as a native plant in Iran (Figure 2) [4].

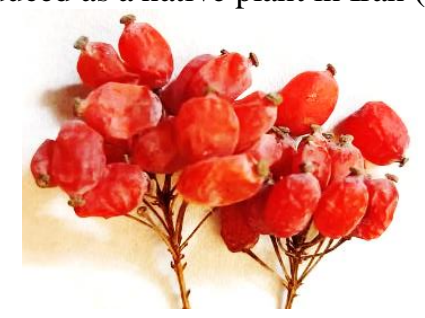

Figure 1. Fresh barberry fruit.

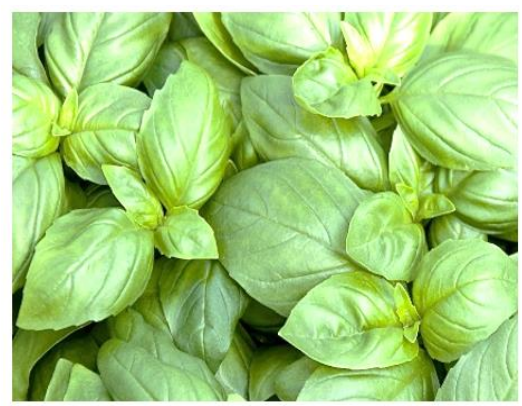

$a$

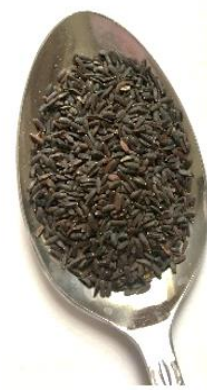

$b$

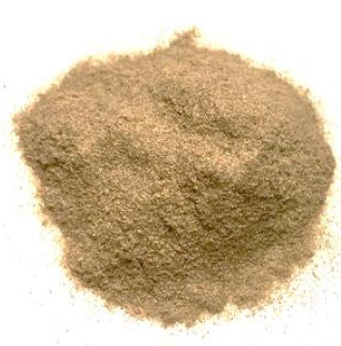

$c$

Figure 2. $a$ - basil plant; $b$ - basil seed; $c$ - basil seed gum powder. 
Polysaccharides extracted from basilicum consist of two main parts of glucomannan $(43 \%)$ with cross links $(1 \rightarrow 4)$ xylan $(24.29 \%)$ and a small portion of glucan $(2.31 \%)$. Also, the presence of arabinogalactan is highly secreted in addition to glucomannan and xylan [5].

Basil gum is a unique hydrocolloid that is classified as anionic gum with $\mathrm{pH}$ 8.1. This gum contains $63.79 \%$ carbohydrates and $32.1 \%$ protein. Glucose, galactose and mannose are $6.29,16.1,9.8 \%$ of the major sugars and potassium with $64.2 \%$ of the major ions present in this gum [6]. In addition to the pseudo-plastic behavior of basil gum, the existence of stress tolerance suggests the ability to suspend particles by this hydrocolloid, which makes it a good stabilizer in some nutritional formulations such as mayonnaise sauce and salad dressings.

Carrageenan, a linear polysaccharide family, is high molecular weight gum extracted from algae mostly from Crispus chondrus red algae and several other types [7].

Commercial solutions of carrageenan are available with the 5-800 $\mathrm{mPa}$ viscosities and measured at a temperature of $75{ }^{\circ} \mathrm{C}$ and a concentration of $1.5 \%(\mathrm{w} / \mathrm{w})$. Solutions with viscosities less than $100 \mathrm{mPa}$ have very close proximity to the Newtonian behavior [8].

Xanthan gum is a high molecular weight extracellular hetero polysaccharide extracted from Xanthomonos campestris. Xanthan is composed of (1-4) $\beta$-D glucose connections and has side chains (two mannose molecules and one glucuronic acid unit), which is available in the form of white powder soluble in cold and hot water. Xanthan gum is widely used in the food industry as a thickener, emulsifier, foaming agent and a temperature resistant stabilizer [9].

Liang et al. (2006) examined the effect of different hydrocolloids on pulp deposition, white sediment, turbidity and viscosity of carrot juice concentrate and concluded that the addition of $0.2 \%$ of guar gum and xanthan gum and $0.3 \%$ of CMC gum and a mixture of $0.015 \%$ and $0.1 \%$ of xanthan gum reduced the amount of pulp deposition and white sediment [10].

Ghannadi, movahhed, \& ahmadi chenarbon (2018) investigated the effect of xanthan and pectin on the stability of suspension of orange juice pulp. According to the results, the amount of suspension of pulp particles in the treatment containing $0.2 \%$ of xanthan was acceptable and the treatment of $0.2 \%$ pectin was favorable in terms of most of the characteristics [11].

Considering the previous studies no published data is found on suspension of barberry pulp in the syrup. The aims of this study were: 1) to study the effect of basil seed gum as a native gum with mixture of carrageenan on suspension of barberry pulp;2) to formulate a barberry suspension in syrup using commercial hydrocolloids.

\section{Materials and methods}

\section{Materials}

Barberry concentrate with brix 65 and acidity of 7.8-8.3 were prepared from khushe Sorkh Company (Iran). Glucose syrup was purchased from Glucose Nemuneh Toos Company (Iran). Carrageenan was purchased from Parand Khorasan Co. (Iran). Basil seed gum was supplied by Reyhan Gum Parsian Company (Iran) and xanthan was purchased from Fu Feng Company (China).

\section{Preparation of barberry suspensions with barberry pulp}

To produce barberry suspensions with barberry pulp, sugar $4.8 \%$ (w/v), glucose syrup $21 \%(\mathrm{w} / \mathrm{v})$, barberry concentrate $17 \%(\mathrm{w} / \mathrm{v})$, water $54 \%(\mathrm{w} / \mathrm{v})$, barberry pulps $2 \%(\mathrm{w} / \mathrm{v})$, were weighed. Different ratios of hydrocolloids $(1.20 \%(\mathrm{w} / \mathrm{v}))$, including basil seed gumcarrageenan and xanthan-carrageenan were prepared (Based on pretests). 
The gum solutions, water, barberry concentrate, sugar, glucose syrup and other ingredients were heated to $60{ }^{\circ} \mathrm{C}$ for 10 minutes. To prepare the final product, the pulps of barberry were directly added to the solution. Ratios were as below:

Ratio of basil seeds gum: carrageenan was (70:30, 30:70, 50:50, 0:100, 100:0) and xanthan-carrageenan was (70:30, 30:70, 50:50, 0:100, 100:0)

\section{Flow behavior and apparent viscosity test}

Flow behavior test for 10 barberry syrup samples with different ratios of carrageenan basil seed gum and carrageenan-xanthan (without pulp) in the shear rate range of $0.1-851 / \mathrm{S}$ were determined using SC4-27 spindle rotary viscometer (RV DVIII Ultra Brookfield. Co, USA) and equipped with a water circulating system (Julabo, Japan). The sample temperature was kept constant at $35^{\circ} \mathrm{C}$ during experiment.

The shear stress was plotted against shear rate in a range of 0.1 to 85 per second. The data obtained were fitted to four different models Newtonian, Power law, Herschel-Bulkley and Sisco) using MATLAB program and the best model (according to the highest Rsquare $\left(\mathrm{R}^{2}\right)$ and the lowest Root Mean Square Error( RMSE) was used to describe flow behavior of the syrup. The apparent viscosity was reported at shear rate of 43/s [12].

\section{Stability test}

To measure the product stability, the amount of $20 \mathrm{~g}$ of each sample (with pulp) was poured into plastic tubes and kept in constant condition at $4{ }^{\circ} \mathrm{C}$. The rate of pulp separations of samples was determined by separating the upper transparent phase and weighing it and its expression based on percentage of total weight of the sample [13] .

\section{Turbidity test}

To measure turbidity, $10 \mathrm{cc}$ of samples were centrifuged for 10 minutes at 1500 rpm.Using centrifuge model 2-16 sigma making Germany. Absorption of the upper portion was measured at $660 \mathrm{~nm}[14]$.

\section{Density test}

A 50-millimeter pycnometer was cleaned with 96-degree ethyl alcohol and washed several times with distilled water. The pycnometer was placed in an oven for 3 hours at 105 $\pm 5^{\circ} \mathrm{C}$. The pycnometer was weighted at $20^{\circ} \mathrm{C}$, and then was filled with freshly boiled and cooled distilled water at $20^{\circ} \mathrm{C}$. The pycnometer was evacuated and dried. It was filled with sample at $20^{\circ} \mathrm{C}$ and weighed as below [15].

Calculation method:

$\mathrm{M}_{1}=$ Weight of pycnometer at $20{ }^{\circ} \mathrm{C}$ in gram

$$
\mathrm{P}=\frac{\mathrm{M} 3-\mathrm{M} 1}{\mathrm{M} 2-\mathrm{M} 1}
$$

$\mathrm{M}_{2}=$ Weight of pycnometer with distilled water at $20^{\circ} \mathrm{C}$ in gram

\section{Brix test}

Refractometer method was used. First, the device (atago, Japan) was adjusted to zero with distilled water. Then, a few drops of sample were placed at $20^{\circ} \mathrm{C}$ on the sample location in a refractometer. Then, the percentage of soluble solids was read as Brix. [15] 


\section{Sensory evaluation}

For sensory evaluation 5 point hedonic test was used. For this purpose, sensory evaluation forms were prepared for 50 panelists (20 to 50 in ages and 31 women and 19 men). For each treatment, a three-digit code was considered. Panelists were asked to give scores between 1 (dislike extremely) to 5 (like extremely). Panelists were asked to drink water between samples [9].

\section{Statistical analysis}

All experiments were performed at least as triplicates. The results of treatments were expressed as mean $\pm \mathrm{SD}$. Data were analyzed and compared using Duncan's multiple range test at significance level of 5\% via SPSS.

\section{Results and discussion}

Effect of basil seed gum, xanthan and carrageenan gum on flow behaviour and apparent viscosity of barberry syrup samples containing barberry pulp

Flow behavior of barberry syrup was determined to predict stability and physical changes. According to the results the data was fitted appropriately to the Herschel-Bulkley model (Higher $\mathrm{R}^{2}$ and the least RMSE) in comparison to other models.

$$
\sigma=K \dot{\gamma}^{n}+\sigma_{0}
$$

where $\sigma$ is shear stress $(\mathrm{Pa}), K$ is the consistency coefficient $\left(\mathrm{Pa} . \mathrm{s}^{\mathrm{n}}\right), \dot{\gamma}$ is shear rate $\left(\mathrm{s}^{-1}\right), \mathrm{n}$ is the flow behavior index and $\sigma_{0}$ is the yield stress $(\mathrm{Pa})$.

The flow behaviour parameters for Herschel-Bulkley model are presented in Table (1). The experimental data indicated that all samples had yield stress. The yield stress means the minimum shear stress to start the flow in a fluid so that at lower values of shear stress the fluid behaves like a solid and is unable to flow [16].

Table 1

Flow behavior Parameters of the Herschel-Bulkley model of barberry syrup containing different concentrations of basil seed gum -carrageenan and xanthan--carrageenan

\begin{tabular}{|c|l|c|c|c|}
\hline $\begin{array}{c}\text { Sample } \\
\text { code }\end{array}$ & \multicolumn{1}{|c|}{ Sample description } & $\boldsymbol{\sigma}_{\mathbf{0}}(\mathbf{p a})$ & $\mathbf{k}\left(\mathbf{p a} . \mathbf{s}^{\mathbf{n}}\right)$ & $\mathbf{n}(-)$ \\
\hline 1 & Basil seed gum70\%- carrageenan30\% & $5.18 \pm 0.33$ & $1.42 \pm 0.05$ & $0.73 \pm 0.02$ \\
\hline 2 & Basil seed gum30\%- carrageenan70\% & $1.38 \pm 0.10$ & $2.76 \pm 0.13$ & $0.57 \pm 0.02$ \\
\hline 3 & Basil seed gum50\%- carrageenan50\% & $1.77 \pm 0.10$ & $4.61 \pm 0.20$ & $0.56 \pm 0.02$ \\
\hline 4 & Basil seed gum0\%-carrageenan100\% & $6.62 \pm 0.46$ & $0.67 \pm 0.09$ & $0.90 \pm 0.03$ \\
\hline 5 & Basil seed gum100\%-carrageenan0\% & $7.51 \pm 0.68$ & $12.4 \pm 1.07$ & $0.36 \pm 0.05$ \\
\hline 6 & Xanthan0\%- carrageenan100\% & $2.36 \pm 0.16$ & $2.18 \pm 0.13$ & $0.44 \pm 0.03$ \\
\hline 7 & Xanthan30\%- carrageenan70\% & $2.42 \pm 0.20$ & $2.05 \pm 0.07$ & $0.45 \pm 0.02$ \\
\hline 8 & Xanthan50\%- carrageenan50\% & $3.26 \pm 0.14$ & $2.00 \pm 0.15$ & $0.45 \pm 0.03$ \\
\hline 9 & Xanthan70\%- carrageenan30\% & $5.06 \pm 0.12$ & $1.49 \pm 0.07$ & $0.58 \pm 0.02$ \\
\hline 10 & Xanthan100\%- carrageenan0\% & $4.50 \pm 0.12$ & $2.71 \pm 0.16$ & $0.49 \pm 0.02$ \\
\hline
\end{tabular}


The results showed that the sample containing the highest amount of basil seed gum $(100 \% \mathrm{w} / \mathrm{v}$ basil seed gum), showed the highest yield stress and the lowest yield stress was related to the sample containing $30 \% \mathrm{w} / \mathrm{v}$ basil seed gum and $70 \% \mathrm{w} / \mathrm{v}$ carrageenan. Such behavior expresses the strong interaction of basil seed gum and other components of the formulation. Sample containing 70\% xanthan and 30\% carrageenan showed the highest yield value (5.06 Pa).

Results indicated that the highest concentration of basil seed gum had the highest effect on the consistency coefficient and flow behavior index. The consistency coefficient of the sample containing the highest concentration of basil seed gum was at the maximum level $(12.4 \mathrm{~Pa} \cdot \mathrm{s})$. In general, consistency coefficient changes in the samples containing basil seed gum was in parallel to the increase in the concentration of the gum except in the sample with $70 \% \mathrm{w} / \mathrm{v}$ of basil seed gum. At this concentration, the hydrocolloid may undergone phase separation and thus have a negative effect on viscosity and consistency. The increase in consistency coefficient in different treatments, especially the treatments containing basil seed gum, may be due to the intermolecular forces and the expansion of hydrogen bonds between water and soluble compounds (basil seed gum), thereby limiting the movement of the water molecule and increasing system consistency [17]. In samples containing xanthan gum the $\mathrm{k}$ values were almost the same in the narrow range of 2 to $2.71 \mathrm{~Pa}$. As shown in the Table 1 , the flow behavior index in all treatments were below 1, indicating a pseudo-plastic and shear thinning behavior of the syrups containing two gums as stabilizers.

In this study, apparent viscosity increased with increasing basil seed gum. The results of statistical analysis of data showed that the combination of basil seed gum-carrageenan gum had a significant effect on the apparent viscosity of the sample compared to the xanthancarrageenan gum composition. One of the reasons is the higher apparent viscosity of carrageenan and basil gum individually compared to xanthan [18].

As shown in Figure 3 the highest apparent viscosity related to sample with 100\% w/v basil seed gum, and the lowest value was for the sample containing 100\% w/v carrageenan. In samples containing xanthan gum-carrageenan, the highest apparent viscosity belonged to sample with $100 \%$ xanthan.

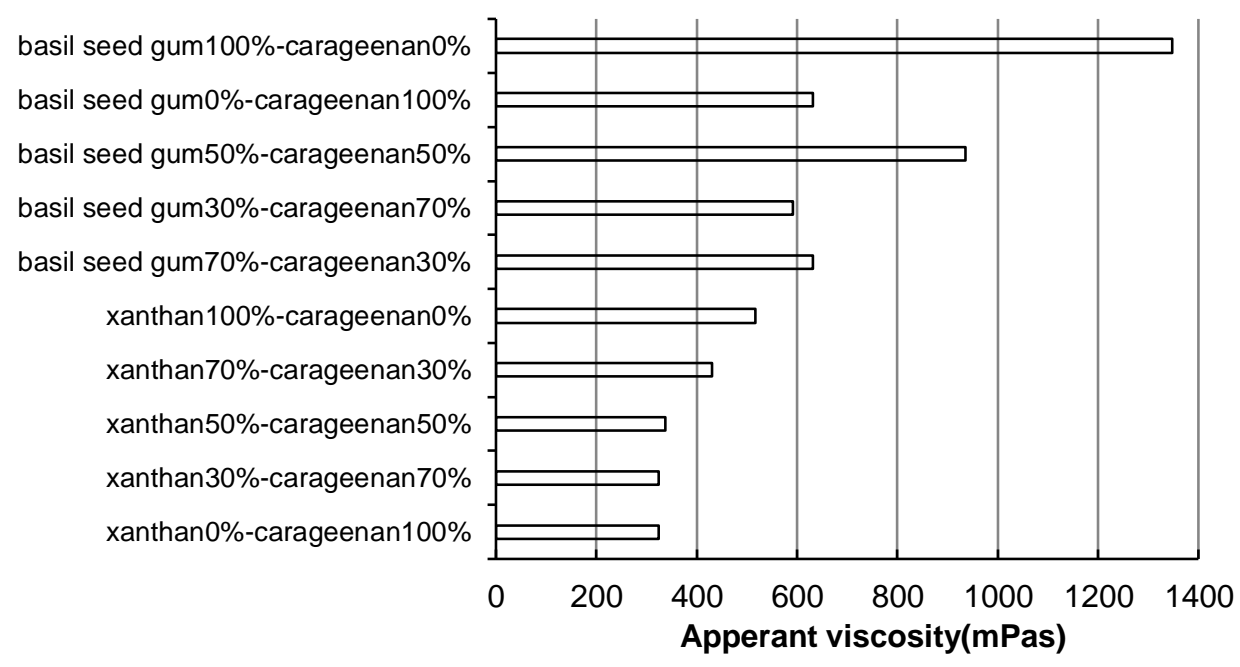

Figure 3. Apparent viscosity of barberry syrup treatments containing different concentrations of basil, carrageenan and xanthan gum as stabilizers 


\section{Effect of adding basil gum, xanthan and carrageenan gum on the stability of barberry syrup containing barberry pulp}

The results showed that among all samples, in the sample $70 \% \mathrm{w} / \mathrm{v}$ basil seed gum and $30 \% \mathrm{w} / \mathrm{v}$ carrageenan, barberry was distributed uniformly throughout the solution from top to bottom, while in other samples, the pulp was not equally distributed and was floating more on top of the syrup. In other samples, barberry pulp couldn't suspend properly due to low viscosity or compact network. Hydrocolloids increase the stability of some food systems by increasing the apparent viscosity of the product or by acting on colloid interactions such as spatial suppression and electrostatic interactions [19]. Therefore, reduce the movement of particles and reduce the speed of the separation of phases from one another [20]. In fact, the reason for uniform distribution in treatments containing carrageenan-basil seed gum was the presence of a three-dimensional network, resulting barley pulp being trapped in this network. Increasing the amount of basil seed gum by formation of a three-dimensional network of continuous phase increases viscosity and make suitable conditions for suspending barberry pulp. Enough force is required to break down the three-dimensional structure of liquid gels. Therefore, the particles should disconnect the existing network and then move it. If a particle is trapped inside this network and the other forces are not enough to disperse the structure of the liquid gel, the particle will remain suspended. Liang et al. (2006) investigated the effect of adding guar, xanthan, gellan, and carboxymethyl cellulose hydrocolloids on the amount of particle precipitation in carrot juice. According to the results, the addition of these gums reduced the amount of sediment in the carrot juice and the concentration of sediment was lower in higher concentrations [10].

\section{Effect of adding basil seed gel, xanthan and carrageenan on turbidity of barberry syrup containing barberry pulp}

According to the results of the Table 2 samples containing basil seed gum-carrageenan compared to xanthan-carrageenan showed higher turbidity. It could be due to the brown color of basil gum compared to white color of xanthan. Also, the reason for the increase of the turbidity in different treatments was the accumulation of double helixes and the trapping of components in the network. Weak gels showed less turbidity in comparison to strong gels. Higher turbidity of the sample containing basil seed gum- carrageenan, may indicate the formation of a stronger gel by these gum compared to the xanthan-carrageenan composition.

Liang et al. (2006) stated that the addition of xanthan, guar, gellan, and carboxymethyl cellulose gums in carrot juice increased turbidity compared to control treatment [10]. In 2011, Kanha also investigated the impact of adding zinc, gellan, pectin and carboxymethyl cellulose gum on ginger drink. The results of this study showed that the addition of pectin and xanthan increased turbidity in treatments compared to control sample and treatments containing gellan and carboxymethyl cellulose [21].

\section{Effect of adding basil gum, xanthan and carrageenan gum on the density of barberry syrup samples containing barberry pulp}

The effect of adding basil seed gum, xanthan, and carrageenan gum on the density of barberry syrup samples containing barberry pulp is shown in Table 2 .

According to the results, the density of samples containing xanthan-carrageenan is lower than samples containing basil seed gum-carrageenan. The highest density belonged to samples containing $100 \% \mathrm{w} / \mathrm{v}$ carrageenan and samples containing $100 \% \mathrm{w} / \mathrm{v}$ xanthan 
showed the lowest density. Density depends on various factors such as concentration of solution, pressure and temperature. In the present study, the reason for increasing the density could be related to increased dry matter and the direct relation of mass with density. The results matched with the results of the research of Tabib Loghmani and Ehsan Doust (2013). They stated that flax and xanthan gum increased the density of ketchup and led to an increase in dry matter content due to the application of gum in the formulation [22].

Effect of adding basil gum, xanthan and carrageenan on Brix of barberry syrup containing barberry pulp

Percentage of soluble solids (Brix) of the samples did not differ significantly with different ratios of xanthan, carrageenan and basil seed gum. Results are shown in Table 2 .

Soluble solids in water measurement results, turbidity and density of samples

\begin{tabular}{|c|l|c|c|c|}
\hline $\begin{array}{c}\text { Sample } \\
\text { code }\end{array}$ & \multicolumn{1}{|c|}{ Sample description } & $\begin{array}{c}\text { Density } \\
(\mathbf{g} / \mathbf{m l})\end{array}$ & $\begin{array}{c}\text { Turbidity } \\
(\mathbf{N T U})\end{array}$ & $\begin{array}{c}\text { Brix } \\
(\%)\end{array}$ \\
\hline 1 & Basilseedgum100\%-carrageenan0\% & $1.1874 \pm 0.01$ & $432.7 \pm 15$ & $40.8 \pm 1$ \\
\hline 2 & Basil seed gum70\%- carrageenan30\% & $1.1965 \pm 0.05$ & $471.3 \pm 20$ & $41.8 \pm 0.5$ \\
\hline 3 & Basil seed gum50\%- carrageenan50\% & $1.1990 \pm 0.04$ & $228.5 \pm 22$ & $42.1 \pm 1$ \\
\hline 4 & Basil seed gum30\%-carrageenan70\% & $1.2069 \pm 0.07$ & $344 \pm 14$ & $41.8 \pm 0.7$ \\
\hline 5 & Basil seed gum0\%-carrageenan100\% & $1.2143 \pm 0.03$ & $329 \pm 10$ & $39.4 \pm 0.5$ \\
\hline 6 & Xanthan0\%- carrageenan100\% & $1.1925 \pm 0.02$ & $88.15 \pm 6$ & $41 \pm 0.6$ \\
\hline 7 & Xanthan30\%- carrageenan70\% & $1.1752 \pm 0.07$ & $135.7 \pm 5$ & $41.8 \pm 1$ \\
\hline 8 & Xanthan50\%- carrageenan50\% & $1.1699 \pm 0.03$ & $135.5 \pm 5$ & $41.2 \pm 0.8$ \\
\hline 9 & Xanthan70\%- carrageenan30\% & $1.1390 \pm 0.04$ & $185.3 \pm 10$ & $40.7 \pm 1$ \\
\hline 10 & Xanthan100\%- carrageenan0\% & $1.0703 \pm 0.02$ & $199 \pm 8$ & $41.6 \pm 1$ \\
\hline
\end{tabular}

Effect of adding basil seed gum, xanthan and carrageenan seeds on the sensory properties of barberry syrup containing barberry pulp

Appearance and taste of the samples were evaluated by the panelists (Table 3). According to previous researches, although hydrocolloids are capable of stabilizing twophase food systems, they can also have negative effects on the final sensory properties [9].

Generally, samples containing $70 \%$ w/v basil seed gum and 30\% w/v carrageenan, due to the proper appearance and appropriate suspension of barberry particles, were scored higher by the panelists, and the lowest scores belonged to the sample containing $100 \% \mathrm{w} / \mathrm{v}$ xanthan gum. The colorless and tasteless properties of xanthan gum was the reason for higher scores in odor and color compared to basil seed gum. In spite of the better color of the samples containing xanthan gum compared to basil seed gum, due to instability of barberry pulp and distribution throughout the sample, these sample were less favorable in terms of appearance and overall acceptance. It is worth mentioning that excessive addition of gum causes undesirable viscosity and therefore reduces the acceptability of the final product from the consumer's point of view, also the high percentage of hydrocolloids decrease the sample's fluidity, which is one of the desirable characteristics [9]. 
Table 3

Results of sensory evaluation of barberry syrup containing different ratios of xanthan, carrageenan and basil seed gum

\begin{tabular}{|c|c|c|c|c|c|c|c|}
\hline 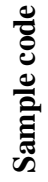 & 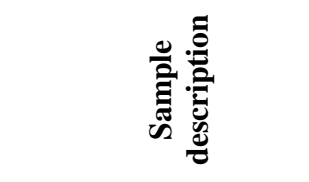 & 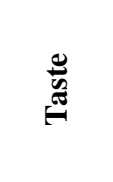 & $\frac{\dot{a}}{\dot{\theta}}$ & $\dot{\bar{o}}$ & 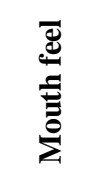 & 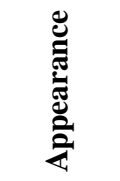 & 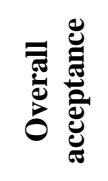 \\
\hline 1 & $\begin{array}{l}\text { Basilseedgum } 100 \% \text { - } \\
\text { arrageenan } 0 \%\end{array}$ & $2 \pm 0.1$ & $2 \pm 0.2$ & $2 \pm 0.1$ & $2 \pm 0.1$ & $3 \pm 0.1$ & $3 \pm 0.3$ \\
\hline 2 & $\begin{array}{l}\text { basil seed gum } 70 \%- \\
\text { carrageenan } 30 \%\end{array}$ & $3 \pm 0.11$ & $3 \pm 0.3$ & $3 \pm 0.1$ & $4 \pm 0.1$ & $4 \pm 0.05$ & $4 \pm 0.14$ \\
\hline 3 & $\begin{array}{l}\text { basil seed gum50\%- } \\
\text { carrageenan } 50 \%\end{array}$ & $3 \pm 0.5$ & $3 \pm 0.1$ & $3 \pm 0.06$ & $2 \pm 0.2$ & $3 \pm 0.14$ & $3 \pm 0.16$ \\
\hline 4 & $\begin{array}{l}\text { basil seed gum } 30 \%- \\
\text { carrageenan } 70 \%\end{array}$ & $3 \pm 0.3$ & $3 \pm 0.1$ & $3 \pm 0.2$ & $3 \pm 0.1$ & $3 \pm 0.18$ & $3 \pm 0.12$ \\
\hline 5 & $\begin{array}{l}\text { basil seed gum0\%- } \\
\text { carrageenan } 100 \%\end{array}$ & $2 \pm 0.08$ & $4 \pm 0.2$ & $3 \pm 0.13$ & $3 \pm 0.1$ & $3 \pm 0.1$ & $3 \pm 0.2$ \\
\hline 6 & $\begin{array}{l}\text { xanthan } 0 \%- \\
\text { carrageenan } 100 \%\end{array}$ & $2 \pm 0.07$ & $3 \pm 0.3$ & $2 \pm 0.3$ & $3 \pm 0.3$ & $3 \pm 0.1$ & $2 \pm 0.1$ \\
\hline 7 & $\begin{array}{l}\text { xanthan } 30 \%- \\
\text { carrageenan } 70 \%\end{array}$ & $2 \pm 0.11$ & $3 \pm 0.05$ & $3 \pm 0.1$ & $3 \pm 0.3$ & $3 \pm 0.08$ & $2 \pm 0.21$ \\
\hline 8 & $\begin{array}{l}\text { xanthan } 50 \%- \\
\text { carrageenan } 50 \%\end{array}$ & $3 \pm 0.09$ & $4 \pm 0.3$ & $3 \pm 0.07$ & $3 \pm 0.1$ & $2 \pm 0.1$ & $2 \pm 0.12$ \\
\hline 9 & $\begin{array}{l}\text { xanthan } 70 \%- \\
\text { carrageenan } 30 \%\end{array}$ & $4 \pm 0.3$ & $4 \pm 0.3$ & $4 \pm 0.3$ & $2 \pm 0.1$ & $3 \pm 0.3$ & $3 \pm 0.3$ \\
\hline 10 & $\begin{array}{l}\text { xanthan } 100 \%- \\
\text { carrageenan } 0 \%\end{array}$ & $4 \pm 0.3$ & $3 \pm 0.3$ & $4 \pm 0.3$ & $3 \pm 0.3$ & $2 \pm 0.1$ & $2 \pm 0.2$ \\
\hline
\end{tabular}

\section{Conclusion}

According to the results, all samples of barberry syrup containing basil seed gumcarrageenan gum and xanthan-carrageenan gum were considered to be non-Newtonian fluids. Herschel-Bulkley was the most suitable model for predicting the flow behavior of the samples.

The results showed that the addition of $70 \% \mathrm{w} / \mathrm{v}$ basil seed gum and $30 \% \mathrm{w} / \mathrm{v}$ carrageenan in the formulation of barberry pulp suspension showed positive effect on pulp particle stability, turbidity, viscosity and was highly accepted by the panelists. The sample containing $100 \% \mathrm{w} / \mathrm{v}$ xanthan gum was scored the lowest in sensory properties. The sample containing $100 \% \mathrm{w} / \mathrm{v}$ basil seed gum showed the highest density and the lowest density was related to sample contaning $100 \%$ w/v xanthan gum. Samples containing xanthancarrageenan showed lower apparent viscosity and stability of barberry pulp was not proper in these samples. Samples containing carrageenan-basil seed gum showed more turbidity than those of xanthan-carrageenan. Total result of this research showed that production of suspended barberry pulp in barberry syrup is possible. This product could be consumed by people in different ages and could benefit from special mouthfeel and nutritional properties. 


\section{References}

1. Balandari A., Cafi M. (2002), Barberry. Production and processing technology, Zaban \& Adab, Mashhad.

2. Mortazavi S.A., Sharifi A., Maskooki A., Niakousari M., Elhamirad A.H. (2014), Optimisation of bioactive compounds extraction from barberry fruit (Berberis vulgaris) using response surface methodology, Research and innovation in science and technology, 3(1), pp. 11-24.

3. Goldfield G.S., Epstein L.H. (2002), Can fruits and vegetables and activities substitute for snack foods?, Health Psychology, 21(3), p. 299.

4. Hosseiniparvar H., Mortazavi A., motamedzadegan A., Razavi M.A., Matia-Merino 1. (2009), Flow behavior of gum solutions extracted from Ocimum basilicum seeds mixed with Locust bean gum and Guar gum, Food processing and storage, 2(1), pp. 84-69.

5. Azuma J.I., Sakamoto M. (2003),Cellulosic hydrocolloid system present in seed of plants, Trends in Glycoscience and Glycotechnology, 15(81), pp. 1-14.

6. Hosseini-Parvar S., Matia-Merino L., Goh K., Razavi S.M.A., Mortazavi S.A. (2010), Steady shear flow behavior of gum extracted from Ocimum basilicum L. seed: Effect of concentration and temperature, Journal of Food Engineering, 101(3), pp. 236-243.

7. Milani J., Maleki G. (2012), Food Industrial Processes-Methods and Equipment ed B. In: Hydrocolloids in food industry, Benjamin Valdez, Intechopen, London.

8. Hashemiravan M., Yarmand M.S.(2008), Application of hydrocolloids in the food industry and other industries, Marze Danesh, Tehran.

9. Arabshirazi S., Movahhed S., Nematti H. (2012), Evaluation of addition of xanthan and hydroxyl propyl methyl cellulose gums on chemical and rheological properties of sponge cakes, Scholars Research Library, 3(2), pp. 589-594.

10. Liang C., Hu X., Ni Y., Wu J., Chen F., Liao X. (2006), Effect of hydrocolloids on pulp sediment, white sediment, turbidity and viscosity of reconstituted carrot juice, Food hydrocolloids, 20(8), pp. 1190-1197.

11. Ghannadi S., Movahhed S., Ahmadi Chenarbon H. (2018), Effect of xanthan gum and pectin on stability of suspension orange juice with pulp, Journal of Food Science \& Technology, (2008-8787), 15(80), pp. 13-23.

12. Razavi M.A., Akbari R. (2009), Biophysical properties of agricultural and food products, Ferdowsi university, Mashhad.

13. Zohuriainpordel S., Aryanfar A. (2015), Effect of Pectin on fixweed Syrup Stabilization, Special Issue of the Twenty-third National Congress of Iranian Food and Science, (In Persian), Islamic Azad University Sabzevar Branch, Quchan.

14. Rivas A., Rodrigo D., Martinez A., Barbosa-Cánovas G., Rodrigo M. (2006), Effect of PEF and heat pasteurization on the physical-chemical characteristics of blended orange and carrot juice, LWT-Food Science and Technology, 39(10), pp. 1163-1170.

15. Anonymous. 2007, Institute of Standard and Industrial Research of Iran (ISIRI), Fruit Juice. Test methods, No: 2685, 1, pp. 13-37.

16. Steffe J.F. (1996), Rheological methods in food process engineering, Freeman press.

17. Soto-Caballero M., Valdez-Fragoso, A., Salinas-López A., Welti-Chanes J., Verardo V., Mújica-Paz H. (2016), Rheological parameters of xanthan gum/pectin solutions as a function of temperature and composition, Revista Mexicana de Ingeniería Química, 15(3), pp. 859-868. 
18. Marcotte M., Hoshahili A. R. T., \& Ramaswamy, H. (2001). Rheological properties of selected hydrocolloids as a function of concentration and temperature, Food Research International, 34(8), pp. 695-703.

19. Foroughinai S., Abbasi S., Hamidiesfahani Z. (2007), The Effect of Single and Combined Additives of Quiche, Saalb and Guar Gum on Dough Stabilization, Journal of Nutrition Sciences and Food Technology of Iran, 2, pp. 15-25.

20. Kiani H., Mousavi S.M.A., Emam-Djomeh Z. (2008), Rheological properties of Iranian yoghurt drink, Doogh, International Journal of Dairy Science, 3(2), pp. 7178.

21. Kanha A. (2011), Use of hydrocolloids in textural stabilization of a yoghurt drink Ayran, Food hydrocolloids, 18, pp. 593-600.

22. Tabibloghmany F.S., Ehsandoost E. (2013), Investigation of Linseed (Linum usitatissimum L.) gum effects on rheological properties, and sensory quality of tomato ketchup during storage, International Journal of Agriculture and Crop Sciences (IJACS), 6(2), pp. 70-76. 